\title{
Food consumption by young adults living in Ribeirão Preto, SP, 2002/2004
}

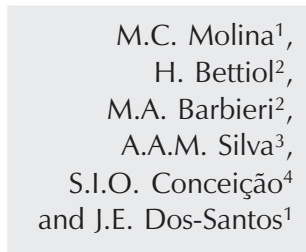

Correspondence

H. Bettiol

Departamento de Puericultura

e Pediatria, FMRP, USP

Av. Bandeirantes, 3900

14049-900 Ribeirão Preto, SP

Brasil

Fax: +55-16-3602 2700

E-mail: hbettiol@fmrp.usp.br

Research supported by CNPq, Fundação de Auxílio ao Ensino,

Pesquisa e Assistência do HC, FMRP, USP (FAEPA), and FAPESP (No. 00/09508-7).

Received November 20, 2006 Accepted July 16, 2007

\author{
'Departamento de Clínica Médica, \\ ${ }^{2}$ Departamento de Puericultura e Pediatria, \\ Faculdade de Medicina de Ribeirão Preto, \\ Universidade de São Paulo, Ribeirão Preto, SP, Brasil \\ ${ }^{3}$ Departamento de Saúde Pública, Universidade Federal do Maranhão, \\ São Luís, MA, Brasil \\ ${ }^{4}$ Coordenação de Nutrição, Centro Universitário do Maranhão, São Luís, \\ MA, Brasil
}

\begin{abstract}
There is evidence showing a close relationship between diet and the occurrence of non-communicable chronic diseases. The present study assessed food consumption in a 2002/2004 cohort of young adults born in 1978/79 in Ribeirão Preto, SP, Brazil. The composition of the habitual diet consumed by a sample of 2063 individuals aged 23-25 years was analyzed using a validated semi-quantitative food frequency questionnaire based on studies of prevention of non-communicable chronic diseases. The Dietsys software was used for dietary calculations. In terms of $\mathrm{WHO} / 2003$ recommendations, there was a high mean daily consumption of energy from fat (consumption: $35.4 \%$; recommendation: $15-30 \%$ ), a low mean intake of energy from carbohydrates $(47.5 \% ; 55-75 \%)$ and a low mean consumption of total fibers $(15.2 \mathrm{~g} ;>25 \mathrm{~g})$. Mean intake of energy from fatty acids $(10 \%$; $<10 \%)$ and protein $(15.6 \% ; 10-15 \%)$ was within recommended limits. When compared to the recommendations of the food pyramid adapted to the Brazilian population, adequate intake was observed only regarding the meat group (consumption: 1.9 portions; recommended: $1-2)$. There was a low consumption of vegetables (2.9; 4-5), fruits (1.2; $3-5)$, breads $(3.6 ; 6-9)$, and dairy products $(1.7 ; 3)$, with excessive fat and sugar intake $(5.7 ; 1-2)$. We conclude that the inadequate food consumption observed in this young population may be associated with the development of excess weight and may contribute to the triggering of non-communicable chronic diseases.
\end{abstract}

\section{Introduction}

The study of the eating habits of a population permits the investigation of the relationship between diet and health status and the identification of risk groups in view of the fact that several studies indicate the importance of the diet both for the prevention
Key words

- Food consumption

- Food frequency

questionnaire

- Food groups

- Feeding habits

- Diet

- Non-communicable diseases of adults 
tive foods. Excessive consumption of coffee, eggs, whole milk products, and saturated and partially hydrogenated fats contributes to increasing the risk of developing cardiovascular diseases. Replacing saturated and trans fatty acids with monounsaturated and polyunsaturated fatty acids seems to be more effective in the prevention of these diseases than a reduction of the total amount of fat consumed (6). Regardless of the source, excessive calorie intake is a risk factor for the development of dyslipidemia, especially hypertriglyceridemia, and for the reduction of high-density serum lipoprotein (7).

Over the last few years, the dietary pattern of the Brazilian population has been changing, with a decreasing relative consumption of various foods, among them legumes, cereals, vegetables, and fruits, and an increasing consumption of refined sugar and soda drinks $(8,9)$. These changes represent important negative traits of the evolution of the dietary pattern (9) which, associated with the introduction of industrialized food products (10), may represent an important risk factor for health $(9,11)$.

In view of the lack of studies on food consumption by the Brazilian population specifically involving young adults, and considering that dietary surveys are preferentially conducted in capital cities and in metropolitan regions, with the dietary pattern of the interior of the country remaining practically unknown, the objective of the present study was to analyze the food consumption of a population of young adults aged 23 to 25 years belonging to a cohort study initiated in 1978/79 in Ribeirão Preto, SP.

\section{Material and Methods}

\section{Study design}

This is a descriptive cross-sectional study of a Ribeirão Preto cohort denoted "Perinatal Health in Ribeirão Preto, São Paulo, Brazil", which investigated 6827 singleton live- born infants delivered by mothers residing in the municipality during the period from June 1, 1978 to May 31, 1979 (12). The present study used data collected during the fourth phase of cohort follow-up from April 2002 to May 2004. Liveborn babies were identified by mother's name and address and by birth date. After 343 known deaths up to 20 years incomplete were excluded, 6484 individuals were eligible for study during adult age. Updated addresses were obtained from the informatized system of registration of medical visits of the Unified Health System (SUS) of Ribeirão Preto, from lists of users of private health plans, and from the evaluation charts of the participants during the previous stages of the study (schoolchildren in 1987/89 and young men recruited for military service at 18 years of age). A total of 5665 individuals belonging to the original cohort were located. Based on the geoeconomic characterization of the city according to four regions defined by the income of the family head, 1 in 3 young adults was contacted by means of fixed telephones, cell telephones and letters explaining the study and containing the telephone number of the research team for contact. After exclusion due to refusal, imprisonment, death from 20 years of age on, or failure to attend the interview, 2063 young adults aged 23/25 years, corresponding to $31.8 \%$ of those eligible for study, participated in the investigation (13). The evaluation was performed in rooms made available for the study at the Blood Center of Ribeirão Preto, with the privacy of the participants being guaranteed throughout the process.

\section{Anthropometric evaluation}

The young adults were weighed and measured according to the techniques recommended by Tanner in 1986 (14). Weight was measured with a Filizola ${ }^{\circledR}$ scale (São Paulo, SP, Brazil) with 100-g graduations and with a $140-\mathrm{kg}$ capacity and height was 
measured with a wood anthropometer with 0.5 -cm markings. Based on body mass index (BMI), the nutritional status of the individuals was classified as follows: underweight (BMI $<18.5 \mathrm{~kg} / \mathrm{m}^{2}$ ); eutrophy or normal weight (BMI between 18.5 and $24.9 \mathrm{~kg} / \mathrm{m}^{2}$ ), overweight (BMI between 25.0 and $29.9 \mathrm{~kg}$ / $\left.\mathrm{m}^{2}\right)$, and obesity (BMI $\left.\geq 30 \mathrm{~kg} / \mathrm{m}^{2}\right)(15)$.

\section{Family income}

Family income was represented by the sum of the income of all family members, divided into tertiles and classified as low, medium and high.

\section{Evaluation of food consumption}

The food frequency questionnaire (FFQ) (16) was used for the study of the previous "habitual" diet, with information being obtained about food intake over the last 12 months. The FFQ was elaborated from a questionnaire validated for the Nippo-Brazilian community of São Paulo (17) which was later adapted for use in programs of prevention of non-communicable chronic diseases directed at adults including the age range involved in this study (18), and excluding food of Japanese origin.

The adapted questionnaire contemplated 75 food items and contained questions about the habitual intake of visible meat fat, of "light" products, and of the type of fat used for meal preparation, and about diet fractionation, with open spaces being left for the mention of foods not included in the list of 75 items but being habitually consumed by the interviewed subject.

The dietary interviews were held by nutritionists after written informed consent was obtained from each participant. The mean habitual frequency of consumption of each food listed in the FFQ was obtained (how many times) together with the respective time unit (daily, weekly or monthly) and the habitual size of the individual portion (17).
The values in grams or volume regarding the limits of the small and large portions (25th and 75th percentiles) were recorded in the space allotted to the portion. Intermediate values within these limits were considered to be medium. A photograph album was used in order to minimize memory bias and to improve the quality of the information about the size of the portions (19).

A Household Measures Manual was elaborated, containing all the measures reported by the subjects and their respective equivalences in weights or volumes. Appropriate instruments were used for this purpose (19-21).

The nutritional value of the diets was analyzed with the Dietsys software, version 4.0 (National Cancer Institute, Bethesda, MD, USA). The list of foods consumed with the respective portion sizes obtained from the FFQ was entered into the software and the calculations of the chemical composition of each food were performed by the program. All nutrients analyzed had correlation coefficients higher than 0.4 based on a previous publication of the FFQ validation (22). Brazilian foods and food preparations complementary to the Dietsys program were added when complete data about them were available from Brazilian tables. Foods with incomplete or doubtful information regarding chemical composition were replaced with foods of similar composition. The results of the dietary calculations were compared to WHO (2003) recommendations (23) for the prevention of diet-related diseases.

\section{Food groups}

In the analysis of the food groups, a daily estimate was obtained of the consumption of "sugar and fats", "vegetables", "fruits", "dairy products", "meats" and "breads, cereals, roots, and tubercles". The legume group was not evaluated because the Dietsys is an American software that includes this group in the meat group, as recommended by the 
American Food Pyramid. Thus, only the nutritional composition of "beans, peas, soy, broad beans, lentils, and chick peas" was analyzed, and not the legume group as a whole.

The results obtained regarding the food groups were compared to the recommendations of the Food Pyramid adapted to the Brazilian population (24) (Figure 1).

\section{Statistical analysis}

Data were analyzed statistically using the Stata 8.0 software. Information about subjects whose daily energy and nutrient intake were below the 1st or above the 99th percentile of the sample itself was excluded in order to avoid over- or underestimation of the distribution of energy and of each nutrient studied. Thus, the study sample varied for each nutrient.

Data regarding proportions, gender and three income fractions in relation to dietary fractionation were analyzed by the chi-square test $\left(\chi^{2}\right)$. The mean number of portions of the food groups consumed was compared to ideal recommendations using the hypothesis test for a mean. The differences in mean nutrients and food groups between men and women and between income fractions were tested by analysis of variance (ANOVA). In all analyses, the level of significance was set at 0.05 . The results are reported as percentages, means $\pm \mathrm{SD}$ or percentiles.

\section{Results}

Of the 2063 individuals studied in the age range of 23-25 years, 995 (48.2\%) were males and $1068(51.8 \%)$ were females. Regarding the nutritional status of the population, the distribution of obesity was similar among men and women (12.8 and $11.1 \%$ ). The proportion of overweight men was almost double that found among women (30.4 and $17.7 \%$ ). The prevalence of underweight women was almost three times that observed among men (8.6 and 2.6\%).

\section{Dietary consumption of the nutrients selected}

Mean energy consumption was 2103.4 kcal, with $25 \%$ of the study population consuming $1638 \mathrm{kcal}$ or less and $75 \%$ consuming a maximum of $2468.7 \mathrm{kcal}$. Analysis of the mean percentages of the caloric contribution of macronutrients and saturated fats and the mean amounts of dietary fibers and cholesterol showed that consumption was not the same as the recommendations for all of them, except cholesterol. Mean protein and saturated fatty acid intake was in the upper limit of adequate amounts. In the following decreasing order, fibers, carbohydrates and lipids were the dietary components consumed in an inadequate manner by the highest percentage of individuals. The amount of fiber $(19 \mathrm{~g})$ that separated the $25 \%$ portion of young adults who presented the highest consumption of this nutrient was lower than recommended amounts. The same occurred for the proportion of carbohydrates in relation to the total calorie intake (51.8\%). In contrast, the value $(31.9 \%)$ that separated the $25 \%$ portion of the population that consumed fewer lipid calories was higher than the maximum recommended amount of fat. Approximately half the population consumed amounts of saturated fatty acids and protein above adequate limits. Cholesterol was the nutrient showing the lowest inadequacy in the diets analyzed (26.7\%). Mean alcohol consumption was $2.7 \%$, with $25 \%$ of the study population consuming $0.8 \%$ or less and $75 \%$ consuming a maximum of $4.1 \%$ (Table 1).

There was a significant difference in total daily calorie consumption between sexes, with men consuming more calories than women. There was no significant difference in the proportion of macronutrients in relation to the total daily energy consumption between sexes. Men ingested fewer satu- 
rated fatty acids and more alcohol, cholesterol and fibers than women (Table 2).

The young adults of higher income consumed a larger total amount of calories than those in the remaining income ranges, as well as larger amounts of carbohydrates, but lower quantities of proteins, saturated fatty acids and alcohol. Those of lower income showed a lower consumption of carbohydrates and a higher consumption of protein, saturated fatty acids and alcohol. There was no significant difference in lipid, cholesterol or fiber consumption between income categories (Table 3).

\section{Consumption of the various food groups}

When the estimated daily intake of each food group by the young adults studied was compared to the recommendations of the "Pirâmide Alimentar Adaptada" (Adapted Food Pyramid) (24), a much lower consumption of breads, vegetables, fruits, milk, and dairy products was observed. The intake of the fat and sugar groups was more than double the ideal recommended amount for a healthy diet (Figure 1).

The mean intake of the vegetable group was higher among women, whereas men

Table 1. Distribution of the components of the habitual diet, alcohol consumption, WHO/FAO (2003) recommendations and percent inadequacy of the diet consumed by young adults aged 23-25 years. Ribeirão Preto, SP, 2002/2004.

\begin{tabular}{|c|c|c|c|c|c|c|}
\hline Diet components & Mean \pm SD & P25 & P50 & P75 & $\begin{array}{c}\text { WHO/FAO } \\
2003 \text { recom- } \\
\text { mendations (\%) }\end{array}$ & $\begin{array}{c}\% \text { Inadequacy in relation } \\
\text { to WHO/FAO } 2003 \\
\text { recommendations }\end{array}$ \\
\hline Energy (kcal) & $2103.4 \pm 648.6$ & 1638.0 & 2011.8 & 2468.7 & - & - \\
\hline Carbohydrates (\%kcal) & $47.5 \pm 6.5$ & 42.9 & 47.3 & 51.8 & $55-75 \%$ & $87.5 \%$ \\
\hline Proteins (\%kcal) & $15.6 \pm 2.9$ & 13.6 & 15.3 & 17.4 & $10-15 \%$ & $55.3 \%$ \\
\hline Lipids (\%kcal) & $35.4 \pm 5.1$ & 31.9 & 35.2 & 38.9 & $15-30 \%$ & $85.3 \%$ \\
\hline $\begin{array}{l}\text { Saturated fatty } \\
\text { acids (\%kcal) }\end{array}$ & $10.0 \pm 2.2$ & 8.5 & 10.0 & 11.5 & $<10 \%$ & $49.0 \%$ \\
\hline Alcohol (\%kcal) & $2.7 \pm 2.5$ & 0.8 & 2.0 & 4.1 & - & - \\
\hline Cholesterol (mg) & $259.2 \pm 126.2$ & 176.2 & 235.2 & 309.5 & $<300 \mathrm{mg}$ & $26.7 \%$ \\
\hline Fibers $(\mathrm{g})$ & $15.2 \pm 6.0$ & 10.7 & 14.5 & 19 & $>25 \mathrm{~g}$ & $93.6 \%$ \\
\hline
\end{tabular}

Data are reported as means $\pm S D, 25$ th, 50th and 75th percentiles or percent.

Table 2. Deviation of the components of the habitual diet and of alcohol consumption by young adults aged 23-25 years in relation to total energy consumption according to gender.

\begin{tabular}{lcr}
\hline Diet components & Male & Female \\
\hline Energy (kcal) & $2313.3 \pm 643.2$ & $1907.8 \pm 590.1^{*}$ \\
Carbohydrates (\%kcal) & $47.4 \pm 6.5$ & $47.5 \pm 6.4$ \\
Proteins (\%kcal) & $15.5 \pm 2.7$ & $15.7 \pm 3.1$ \\
Lipids (\%kcal) & $35.1 \pm 5.1$ & $35.6 \pm 5.1$ \\
Saturated fatty acids (\%kcal) & $9.9 \pm 2.2$ & $10.2 \pm 2.2^{*}$ \\
Alcohol (\%kcal) & $3.1 \pm 2.3$ & $2.0 \pm 2.0^{*}$ \\
Cholesterol (mg) & $285.9 \pm 113.5$ & $224.8 \pm 93.7^{*}$ \\
Fibers (g) & $16.4 \pm 6.0$ & $14.0 \pm 5.7^{*}$ \\
\hline
\end{tabular}

Data are reported as means \pm SD.

${ }^{*} \mathrm{P}<0.05$ compared to males (ANOVA). 
consumed more breads, fats and sugar, meat, and alcoholic beverages. There was no difference between sexes in the intake of the fruit and milk groups (Figure 2).

\section{Discussion}

The anthropometric evaluation of young adults revealed a high prevalence of underweight among women and a low prevalence among men (15). When compared to data obtained by the "Pesquisa de Orçamentos Familiares 2002-2003 (POF)" (Survey of Family Budgets 2002-2003) (25), the preva- lence of overweight was high and predominated among men, and the prevalence of obesity was higher than that observed for Brazil as a whole in both sexes. Obesity, considered to be a problem of multiple etiology, is related, among other factors, to inadequate dietary practices (23) involving excessive consumption of high energy density foods.

The nutrient consumption by a large proportion of the young adults studied here was outside the recommended ranges. There was inadequate mean intake of lipid, carbohydrate and total fiber calories. The mean fatty
Figure 1. Recommended consumption and mean number of portions of the food groups consumed by the young adults studied. ${ }^{*} \mathrm{P}<0.05$ (one sample $t$-test comparing the mean study values with the recommendations of the food pyramid adapted to the Brazilian population; 24)
Table 3. Components of the habitual diet and of alcohol consumption by young adults aged 23-25 years in relation to total energy consumption according to family income.

\begin{tabular}{lccc}
\hline Diet components & \multicolumn{3}{c}{ Family income } \\
\cline { 2 - 4 } & Low $(\mathrm{N}=681)$ & Medium $(\mathrm{N}=631)$ & High $(\mathrm{N}=600)$ \\
\hline Energy (kcal) & $2060.4 \pm 607.2$ & $2083.2 \pm 625.7$ & $2141.7 \pm 683.9$ \\
Carbohydrates (\%kcal) & $46.2 \pm 6.2$ & $47.2 \pm 6.4$ & $48.5 \pm 6.6^{*}$ \\
Proteins (\%kcal) & $16.6 \pm 2.7$ & $15.7 \pm 3.0$ & $14.6 \pm 2.7^{*}$ \\
Lipids (\%kcal) & $35.3 \pm 5.0$ & $35.4 \pm 5.0$ & $35.5 \pm 5.3$ \\
Saturated fatty acids (\%kcal) & $10.3 \pm 2.1$ & $10.0 \pm 2.1$ & $9.9 \pm 2.3^{*}$ \\
Alcohol (\%kcal) & $2.7 \pm 2.2$ & $2.6 \pm 2.3$ & $2.3 \pm 2.0^{*}$ \\
Cholesterol (mg) & $258.6 \pm 106.7$ & $255.5 \pm 107.8$ & $249.6 \pm 106.5$ \\
Fibers (g) & $14.8 \pm 5.9$ & $15.2 \pm 6.2$ & $15.6 \pm 5.9$ \\
\hline
\end{tabular}

Data are reported as mean \pm SD. A total of 151 cases of unknown income were excluded. ${ }^{*} \mathrm{P}<0.05$ compared to low and medium (ANOVA).

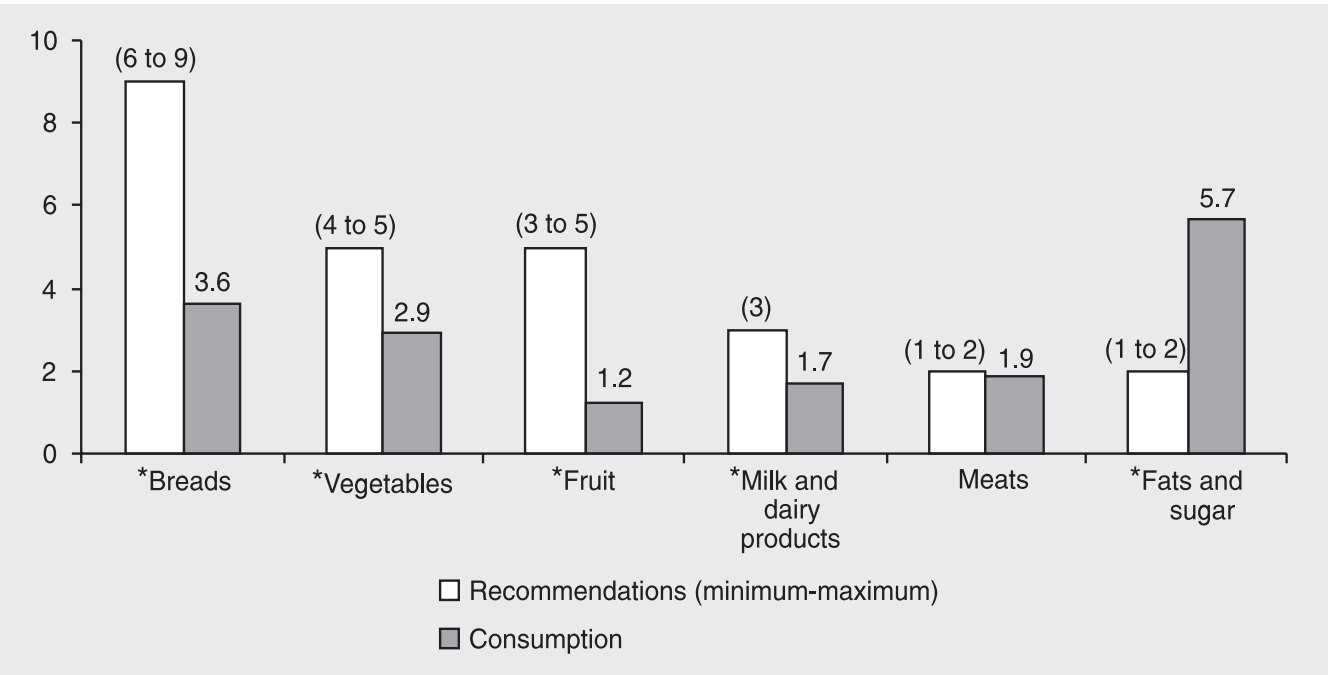


acid and protein calorie values were within the upper limits recommended. Regarding the mean total energy content of the diet consumed, results similar to the present ones were obtained in studies conducted on individuals aged 20 to 40 years in Cotia, SP, Brazil (26) and on American adolescents (27). Energy intake was also found to be higher among men, in agreement with data reported by others $(26,28,29)$.

The energy contribution by carbohydrates was found to be lower, the contribution by lipids was found to be higher and the contribution by proteins was in the upper limit of WHO 2003 recommendations (23). The Ribeirão Preto findings were different from those obtained in a 1990 study conducted in the municipality of Cotia, SP, on individuals predominantly in the 20- to 40-year age range, in which macronutrient intake was within adequate ranges (26). The dietary inadequacies observed in the present study may possibly reflect unfavorable tendencies in the dietary pattern due to the excessive consumption of total and saturated fats (30), especially in the young population aged 19 to 25 years (28).

The tendency to a reduction of carbohydrates and an increase in the proportion of proteins and lipids in the diet has been demonstrated in several countries as well as in Brazil (26). In the presence of insufficient carbohydrate intake, protein utilization by the organism may be deviated from its major function in order to generate energy (31).

Almost $50 \%$ of the young adults studied here presented inadequate consumption of calories from saturated fatty acids ( $>10 \%)$, a proportion similar to those obtained in studies in other Brazilian cities (28). Among adults from Bambuí, MG, the contribution of saturated fatty acid calories on a percent basis (29) was adequate, as opposed to the mean $10 \%$ value for the young adults from Ribeirão Preto, which was similar to the mean value reported in the American study (11\%) for both sexes (27). Regarding family income, saturated fatty acid intake was higher among lower income young adults, in contrast to the results obtained in Minas Gerais (29).

The above studies $(26,27)$ detected an adequate mean cholesterol intake and a greater intake by men, similar to the results obtained in the present study. However, 25\% of the individuals in the present study ingested greater than recommended daily quantities of cholesterol and saturated fatty acids corresponding to an atherogenic diet, i.e., a diet with high lipid and saturated fatty acid contents which increases the risk for obesity, dyslipidemia and cardiovascular diseases.

Alcohol consumption was higher among low-income individuals and among men, as also reported in other studies $(29,32)$. However, alcohol intake by young adults was higher than that observed in Bambuí (29).

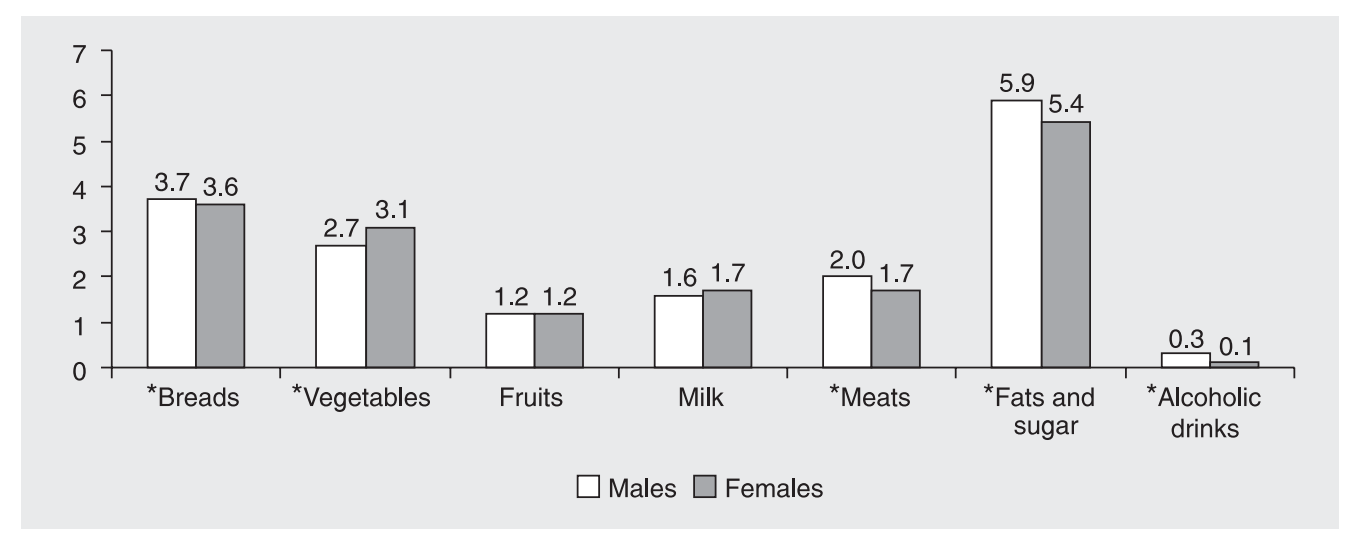

Figure 2. Mean number of portions of the food groups habitually consumed by young adults aged $23 / 25$ years, according to gender. ${ }^{*} P<0.05$ compared to females (Student $t$-test). 
The difference in the intake of the percentage of calories derived from alcohol between genders in Bambuí (1.7\% for men and $0.4 \%$ for women) was about 4-fold higher than in the Ribeirão Preto study (3.1 and $2 \%$ ), in which the intake was about 1.5 times higher in men. In another study, when the calories from alcohol were excluded from the statistical analysis, the total mean calorie value of the diet was reduced from approximately 2800 to about 1900 calories. It should be emphasized that the frequent intake of alcohol is a public health problem from a nutritional viewpoint, more because it replaces the energy of other food source nutrients than simply because of the consequences of its excessive intake (32).

Fiber intake has been found to be below recommended values in various investigations. In a study on adults, the mean daily total fiber consumption was $24 \mathrm{~g}$ (33), a much higher value than that observed in the present study (15.2 g), but still lower than recommended. In both studies, fiber consumption was greater among men. The 1987/ 88 POF data of IBGE showed inadequate intake of total food fiber in all 11 metropolitan regions studied (34). Regarding the daily portions of each food group consumed, only meat intake was found to be adequate. There was insufficient intake of vegetables, fruits, breads, and milk, with a worrisome and excessive ingestion of fats and sweets in relation to the recommendations.

Several investigations have shown distortion between real and recommended consumption for the number of portions of each food group. A high consumption of fats and sugar was observed $(35,36)$, similar to the findings of the present study, as well as insufficient consumption of the group of breads and vegetables (36). A study conducted on American adolescents revealed that neither sex reached the intake of the portions recommended by the American Food Pyramid, except for dairy products (27). The excess detected in the present in- vestigation regarding the group of sweets and fats seems to reflect the fact that in the habitual form of preparation of meals for adults and young people there is an undue utilization of oils and fats, a preference for fried foods, as well as an elevated ingestion of sweet desserts, drinks containing sugar and soda drinks. The need to alert the population to the health risks resulting from the indiscriminate intake of foods such as oils, fats, sugars, and sweets is emphasized.

A study conducted in the State of Bahia among young individuals aged 17 to 19 years revealed habitual consumption of rice, beans, manioc flour, French bread, butter, margarine, sugar, and coffee and a low consumption of dairy products, fruits, legumes, and vegetables (37), with this low consumption being similar to that observed in the present study.

A study of the consumption of fruits and vegetables conducted by the Oswaldo Cruz Foundation in Brazil in a population of 5000 individuals older than 18 years showed that a minority $(13.5 \%)$ reached the nutritional recommendations of consuming five or more daily portions of these foods (3). In the present study, the mean number of portions of vegetables and fruits consumed per day by the young adults was lower than recommended. The two studies showed insufficient intake of fruits and vegetables by young adults of both sexes.

In an investigation of adults carried out in Japan, women reported a more frequent consumption of fruits, vegetables and sweets and a lower consumption of rice compared to men, but also a lower preference for salty and fatty foods than men. On the basis of the analyses of the remaining foods, including those characteristic of the country, and also of the nutrient analyses, the authors concluded that women had a more adequate dietary pattern than men (38). This may be probably due to the scientific evidence that an adequate intake of fruits and vegetables (greater among women) contributes to a re- 
duction of the risk of non-communicable chronic diseases and that inadequate intake of salt and fat (greater among men) is directly associated with the risk for these diseases (23).

The consumption of vegetables and fruits increases with age (3), possibly owing to the fact that older individuals established their eating habits during a period when the "modern eating habit", characterized by a high consumption of fat, sugar and salt and the lack of complex carbohydrates, fibers and micronutrients, was less pronounced.

Epidemiologic evidence (23) has shown that a high fiber intake contributes to reducing the risk of weight gain and obesity and of developing type II diabetes. Saturated fats probably contribute to an increase in the risk of developing type II diabetes, with total fat intake possibly promoting the disease. The consumption of an adequate amount of fruits and vegetables (400-500 g/day) and a low to moderate ingestion of alcohol are recommended in order to reduce the risk of cardio- vascular disease, with a high alcohol ingestion being a predictive factor of an increased risk of cardiovascular disease. Dietary cholesterol is a risk factor for the increased risk of cardiovascular disease. Regarding some types of malignant neoplasias, it should be pointed out that the risk of developing them is probably reduced by a high intake of fruits and vegetables, although recent studies on postmenopausal women have raised doubts about this effect regarding cancer of the colon and of the breast $(39,40)$.

It can be seen that the eating habits of this young population may be associated with the development of excess weight and contribute to the onset of non-communicable chronic diseases. The results reported here are applicable to public health in terms of the understanding of a relevant problem. It is of fundamental importance to invest in strategies aiming at a change in dietary habits and life style, contributing to an improved quality of life and to the future health of young adults.

\section{References}

1. Vasconcellos MT, dos Anjos LA. Energy adequacy ratio (intake/ requirements) as an indicator of families nutritional assessment: a critical analysis of methods applied to food consumption surveys. Cad Saúde Pública 2001; 17: 581-593.

2. Cervato AM, Vieira VL. Consumo alimentar: como avaliar a qualidade. Nutrição em Pauta 2003; 62: 12-16.

3. Jaime PC, Monteiro CA. Fruit and vegetable intake by Brazilian adults, 2003. Cad Saúde Pública 2005; 21 (Suppl): 19-24.

4. Willett WC. Diet and health: what should we eat? Science 1994; 264: 532-537.

5. Mann Jl. Diet and risk of coronary heart disease and type 2 diabetes. Lancet 2002; 360: 783-789.

6. Hu FB, Rimm EB, Stampfer MJ, Ascherio A, Spiegelman D, Willett WC. Prospective study of major dietary patterns and risk of coronary heart disease in men. Am J Clin Nutr 2000; 72: 912-921.

7. Lenz TL. Therapeutic lifestyle changes and pharmaceutical care in the treatment of dyslipidemias in adults. J Am Pharm Assoc 2005; 45: 492-499.

8. Mondini L, Monteiro CA. Changes in the diet pattern of the Brazilian urban population (1962-1988). Rev Saúde Pública 1994; 28: 433-439.

9. Monteiro CA, Mondini L, Costa RB. Changes in composition and appropriate nutrition of family diet in the metropolitan areas of Brazil (1988-1996). Rev Saúde Pública 2000; 34: 251-258.
10. Bleil SI. O padrão alimentar ocidental: considerações sobre a mudança de hábitos no Brasil. Cad Debate 1998; 6: 1-25.

11. Monteiro CA, Mondini L, de Souza AL, Popkin BM. The nutrition transition in Brazil. Eur J Clin Nutr 1995; 49: 105-113.

12. Haeffner LS, Barbieri MA, Rona RJ, Bettiol H, Silva AA. The relative strength of weight and length at birth in contrast to social factors as determinants of height at 18 years in Brazil. Ann Hum Biol 2002; 29: 627-640.

13. Barbieri MA, Bettiol H, Silva AA, Cardoso VC, Simoes VM, Gutierrez MR, et al. Health in early adulthood: the contribution of the 1978/79 Ribeirão Preto birth cohort. Braz J Med Biol Res 2006; 39: 10411055.

14. Tanner JM. Normal growth and techniques of growth assessment. Clin Endocrinol Metab 1986; 15: 411-451.

15. WHO (World Health Organization). Physical status: The use and interpretation of anthropometry. Geneva: WHO. Technical Report Series, No. 854; 1995.

16. Pereira RA, Koifman S. Using food frequency questionnaire in past dietary intake assessment. Rev Saúde Pública 1999; 33: 610-621.

17. Cardoso MA, Stocco PR. Development of a quantitative questionnaire of food intake in Japanese immigrants and their descendants residents in São Paulo, Brazil. Cad Saúde Pública 2000; 16: 107114. 
18. Ribeiro $A B$, Cardoso MA. Construção de um questionário de freqüência alimentar como subsídio para programas de prevenção de doenças crônicas não transmissíveis. Rev Nutr 2002; 15: 239-245.

19. Zabotto CB, Viana RP, Gil MF. Registro fotográfico para inquéritos dietéticos: utensílios e porções. Campinas: Unicamp; 1996.

20. Pinheiro ABV, Lacerda EMA, Benzecry EH, Gomes MCS, Costa VM. Tabela para avaliação de consumo alimentar em medidas caseiras. 2nd edn. São Paulo: Editora Atheneu; 1994.

21. Universidade Federal de Viçosa. Diet Pro. [Computer program]. Versão 3.0.2001.

22. Crispim SP, Franceschini SCC, Priore SE, Fisberg RM. Validação de inquéritos dietéticos: uma revisão. Nutrire 2003; 26: 127-141.

23. WHO/FAO. Diet nutrition and the prevention of chronic diseases. Report of a Joint WHO/FAO Expert Consultation. Geneva: World Health Organization (WHO Technical Report Series, No. 916); 2003.

24. Philippi ST, Ribeiro LC, Latterza AR, Cruz ATR. Pirâmide alimentar adaptada; guia para escolha dos alimentos. Rev Nutr 1999; 12: 6580.

25. Instituto Brasileiro de Geografia e Estatística. Pesquisa de Orçamentos Familiares - POF 2002-2003. http://www.ibge.gov.br. Accessed December 22, 2004.

26. Cervato AM, Mazzilli RN, Martins IS, Marucci MF. Regular diet and cardiovascular disease risk factors. Rev Saúde Pública 1997; 31: 227-235

27. Rockett HR, Berkey CS, Field AE, Colditz GA. Cross-sectional measurement of nutrient intake among adolescents in 1996. Prev Med 2001; 33: 27-37.

28. Galeazzi MAM, Domene SMA, Sichieri R. Estudo multicêntrico sobre consumo alimentar e estado nutricional. Brasília: Cadernos de Debate. Instituto Nacional de Alimentação e Nutrição, Ministério da Saúde/Núcleo de Estudos em Alimentação, Universidade Estadual de Campinas; 1997.

29. Bonomo E, Caiaffa WT, Cesar CC, Lopes AC, Lima-Costa MF. Food intake according to socioeconomic and demographic profile: the Bambuí Project. Cad Saúde Pública 2003; 19: 1461-1471.

30. Levy-Costa RB, Sichieri R, Pontes NS, Monteiro CA. Household food availability in Brazil: distribution and trends (1974-2003). Rev Saúde Pública 2005; 39: 530-540.

31. Yuyama L, Aguiar J, Macedo S, Alencar F, Nagahama D, Favaro D, et al. Avaliação da alimentação de pré-escolares de Barcelos e Ajuricaba, estado do Amazonas. Rev Inst Adolfo Lutz 2002; 59: 2732.

32. Dressler WW, Ribeiro RP, Balieiro MC, Oths KS, Dos Santos JE. Eating, drinking and being depressed: the social, cultural and psychological context of alcohol consumption and nutrition in a Brazilian community. Soc Sci Med 2004; 59: 709-720.

33. Mattos LL, Martins IS. Dietary fiber consumption in an adult population. Rev Saúde Pública 2000; 34: 50-55.

34. Turano W, Louzada SRN, Derevi SCN, Mendez MHM. Estimativa de consumo diário de fibra alimentar na população adulta, em regiões metropolitanas do Brasil. Nutr Bras 2002; 1: 130-135.

35. Nuzzo L. Avaliação do estado nutricional de adolescentes de uma escola privada de ensino. [Master's thesis]. São Paulo: Faculdade de Saúde Pública, USP; 1998.

36. Speck BJ, Bradley CB, Harrell JS, Belyea MJ. A food frequency questionnaire for youth: psychometric analysis and summary of eating habits in adolescents. J Adolesc Health 2001; 28: 16-25.

37. Santos JS, Costa MCO, Nascimento Sobrinho CL, Silva MCM, Souza KEP, Melo BO. Anthropometric profile and food intake of adolescents in Teixeira de Freitas - Bahia, Brazil. Rev Nutr 2005; 18: $623-632$.

38. Iso $\mathrm{H}$, Date $\mathrm{C}$, Noda $\mathrm{H}$, Yoshimura T, Tamakoshi A. Frequency of food intake and estimated nutrient intake among men and women: the JACC Study. J Epidemiol 2005; 15 (Suppl 1): S24-S42.

39. Beresford SA, Johnson KC, Ritenbaugh C, Lasser NL, Snetselaar LG, Black HR, et al. Low-fat dietary pattern and risk of colorectal cancer: the Women's Health Initiative Randomized Controlled Dietary Modification Trial. JAMA 2006; 295: 643-654.

40. Prentice RL, Caan B, Chlebowski RT, Patterson R, Kuller LH, Ockene JK, et al. Low-fat dietary pattern and risk of invasive breast cancer: the Women's Health Initiative Randomized Controlled Dietary Modification Trial. JAMA 2006; 295: 629-642. 